\title{
INTERPRETASI OBJEK WISATA DI TAMAN WISATA ALAM CANI SIRENRENG, KABUPATEN BONE
}

\author{
Interpretation of Tourist Attraction at Cani Sirenreng Nature Tourism Park, \\ Bone Regency \\ Risma Illa Maulany ${ }^{1}$, Muhammad Fiqhi Rahman², Amran Achmad ${ }^{1 凶}$ \\ ${ }^{1}$ Staf Pengajar, Fakultas Kehutanan Universitas Hasanuddin Makassar Universitas Hasanuddin Makassar \\ ${ }^{2}$ Mahasiswa, Laboratorium Konservasi Sumber Daya Hutan dan Ekowisata, Fakultas Kehutanan \\ ${ }^{\triangle}$ corresponding author: amhutan@yahoo.com
}

\begin{abstract}
Cani Sirenreng Nature Tourism Park is located in the Bone Regency which is under managed of Bureau Agency of the Conservation of The Natural Resources of South Sulawesi. This research aims to develop materials for the purposes of the interpretation of natural attractions in Cani Sirenreng Nature Tourism Park. The tourism object of Cani Sirenreng Nature Tourism Park was studied based on block utilization. The tourism object interpreted are physical, biological (flora and fauna) and socialcultural around the park. The first track was the track to Baruttunge Waterfall which became the main object with a height of $70 \mathrm{~m}$ waterfall, which is formed on the three levels of waterfalls. The second track was the track to Coppo Cempa which featuring rows of hills and panoramic sunrise or sunset. In the track of Coppo Cempa, there were 27 species of birds found here including Sulawesi Serpent Eagle and Rofous Wingged Buzzard which were protected under the regulation. Direct interaction with the community around and viewing direct harvesting of nira of sugar palm can also be done in this track. This information can be used as the interpretation material to visitors coming to Cani Sirenreng Nature Tourism Park
\end{abstract}

Key words: Nature Tourism Park; potential of nature tourism; track (interpretation) tourism.

\section{A. PENDAHULUAN}

Ekowisata adalah suatu bentuk perjalanan wisata alam yang dilakukan dengan tujuan untuk konservasi lingkungan dan pelestarian kehidupan dan kesejahteraan penduduk setempat (Fandeli, dkk, 2000). Awalnya ekowisata dilakukan oleh wisatawan pecinta alam yang menginginkan agar daerah tujuan wisata tetap utuh dan lestari, di samping budaya dan kesejahteraan masyarakatnya tetap terjaga (Machmud, 2010). Seiring dengan perkembangannya, ekowisata merupakan suatu bentuk wisata yang sangat erat dengan prinsip konservasi.

Untuk mencapai tujuan tersebut perencanaan pengeloaan daerah wisata alam dibangun melalui pendekatan pelestarian dan pemanfaatan. Salah satu satu strategi perencanaan pengelolaan yang dikembangkan dalam kegiatan ekowisata adalah interpretasi. Menurut Soedargo, dkk. (1989) interpretasi adalah seni dalam menjelaskan keadaan lingkungan kepada pengunjung yang datang ke tempat wisata sehingga pengunjung yang datang bertambah pengetahuannya dan menyadari serta melestarikan lingkungan tempat wisata tersebut. Hal ini diharapkan agar pelaku wisata alam nantinya dapat mengenal alam dan sistemnya sehingga kesadaran mereka untuk menjaga alam lebih meningkat lagi. Hal ini merupakan peluang yang sangat baik untuk pengelolaan sumber daya alam yang berkelanjutan.

Salah satu tempat yang menjadi sarana dalam kegiatan ekowisata adalah Taman Wisata Alam. Taman Wisata Alam sebagai kawasan pelestarian alam yang terutama dimanfaatkan untuk pariwisata dan rekreasi alam (Departemen Kehutanan, 1990). Salah satu contoh rekreasi alam yang dilakukan di Taman Wisata Alam adalah berkemah. Kegiatan ini bertujuan untuk memberi kesenangan dan juga memberi manfaat edukasi terkait dengan kondisi alam.

Taman Wisata Alam Cani Sirenreng terletak di Kabupaten Bone, Provinsi Sulawesi Selatan. Mengacu pada data BKSDA Sulsel (2013) bahwa daya tarik utama ditetapkannya sebagai TWA adalah kondisi alam/vegetasi yang masih bagus serta memiliki kekayaan alam baik flora maupun fauna yang cukup tinggi dan adanya air terjun bertingkat sebagai objek ekowisata. Air terjun ini berada di Desa Cani Sirenreng, Kecamatan Ulaweng, Kab. Bone. Air terjun ini juga dikenal dengan nama Air terjun Baruttunge. Selain air terjun, TWA Cani Sirenreng juga memiliki puncak bukit bernama Coppo Cempa yang saat ini banyak pengunjung datang untuk menikmati pemandangan dengan berkemah. Potensi wisata lainnya adalah sosial budaya seperti atraksi tradisional yang terdapat di sekitar 
Taman Wisata Alam Cani Sirenreng, atraksi ini merupakan kegiatan tahunan yang di lakukan oleh masyarakat untuk menyambut datangnya musim panen. Kegiatan ini disebut Massempe' dimana para pemuda desa bersama-sama meperagakan aksi beladiri yang hanya menggunakan kaki. Ini menjadi salah satu atraksi budaya yang dimiliki Kabupaten Bone. Jarak yang harus ditempuh dari Kota Watampone sekitar $\pm 20 \mathrm{Km}$ dengan waktu tempuh \pm 30 Menit.

Namun hingga saat ini, belum banyak digali informasi terkait potensi wisata dan lainnya dalam mendukung pengembangan ekowisata di kawasan tersebut. Selain itu, informasi yang ada belum dikemas dalam paket interpretasi yang komprehensif. Melihat beberapa potensi ekowisata yang ada di TWA Cani Sirenreng, maka dipandang perlu untuk mengumpulkan data dan informasi sekaligus menyusun bahan interpretasi yang efektif dan efisien agar pengunjung yang hadir dapat menikmati dan mendapatkan pengetahuan terkait dengan kekayaan sumber daya alam guna mendukung kegiatan pengembangan ekowisata di Taman Wisata Alam Cani Sirenreng.

Penelitian ini bertujuan untuk menyusun bahan bagi keperluan interpretasi objek wisata alam di Taman Wisata Alam Cani Sidendreng, Kab.Bone, Prov. Sulawesi Selatan. Kegunaan dari penelitian ini diharapkan dapat memberi informasi mengenai karakteristik objek wisata pada pengelola kawasan taman wisata alam cani sidendreng dalam mengembangkan kawasan tersebut sebagai areal kegiatan ekowisata yang informatif.

\section{B. METODE PENELITIAN}

Penelitian ini dilaksanakan pada bulan JanuariFebruari 2016 di Taman Wisata Alam (TWA) Cani Sirenreng, Kabupaten Bone, Provinsi Sulawesi Selatan. Penelitian ini tepatnya dilakukan pada blok pemanfaatan TWA Cani Sirenreng sebagai blok yang dimanfaatkan untuk kegiatan wisata.

Pengambilan data potensi fisik dilakukan dengan pengambilan titik koordinat setiap potensi fisik dan pengukuran dimensi berupa tinggi dan lebar air terjun serta mengumpulkan foto objek. Kemudian dilakukan wawancara kepada kepala desa dan tokoh masyarakat untuk pengumpulan data berupa sejarah dan hal unik mengenai potensi fisik tersebut. Data potensi biologi berupa flora dan fauna

1) Pengambilan data potensi wisata flora dilakukan pada jalur wisata. Jalur wisata terdiri atas 2 jalur ; jalur 1 menghubungkan pintu gerbang ke air terjun sepanjang $500 \mathrm{~m}$, sedangkan jalur 2 menghubungkan pintu gerbang ke areal perkemahan sepanjang $1,3 \mathrm{~km}$. Plot berukuran 10 x $10 \mathrm{~m}$ diletakkan dengan menggunakan sistematik sampling pada setiap 100 meter di jalur wisata. Pengambilan plot dilakukan dengan contoh yang berbeda pada masing - masing tingkatan pertumbuhan. Untuk tingkatan pohon plot yang digunakan berukuran $10 \times 10 \mathrm{~m}$, sedangkan ukuran $5 \times 5 \mathrm{~m}$ untuk tingkatan tiang, $2 \times 2 \mathrm{~m}$ untuk tingkatan pancang. Tingkatan semai dihitung dan diukur pada plot $1 \times 1 \mathrm{~m}$. Jadi, jalur 1 menghasilkan 3-4 plot, sedangkan jalur 2 menghasilkan 6 plot. Variabel yang akan diamati adalah: nama jenis, keliling pohon, tingkatan pertumbuhan. Variabel yang diamati kemudian dimasukkan pada tally sheet flora.

2) Pengambilan data potensi wisata fauna dilakukan dengan metode transek garis dengan menentukan jalur yang akan dilalui yaitu dari awal masuk tracking hingga objek wisata. Jalur yang dilalui terdiri atas 2 jalur transek. Jalur transek 1 menghubungkan pintu gerbang ke air terjun dengan jarak $500 \mathrm{~m}$, sedangkan jalur transek 2 menghubungkan pintu gerbang ke areal perkemahan dengan jarak $1,3 \mathrm{~km}$. Setiap plot dibagi menjadi beberapa sub-plot yang berukuran $100 \mathrm{~m}$. Pengamatan dilakukan sambil berjalan, satwa yang ditemukan ditentukan jarak antara satwa dan pengamat. Hasil pengamatan satwa yang ditemukan dicatat pada tally sheet yang berisi informasi mengenai titik koordinat awal dan akhir dari masing - masing jalur tracking, waktu awal dan akhir pengumpulan data, cuaca, jenis satwa, jumlah satwa, waktu kemunculan satwa, lalu didokumentasikan. Pengumpulan data jenis satwa dilakukan pada pagi hari dan sore hari antara pukul $07.00-10.00$ Wita dan pukul 15.00 - 17.30 Wita sebanyak tiga kali pengulangan untuk setiap transek jalur.

Pengambilan sosial budaya masyarakat sekitar TWA Cani Sirenreng dengan melakukan wawancara langsung kepada pemerintah desa, tokoh masyarakat dan elemen masyarakat lainnya terkait budaya lokal masyarakat. Adapun poin-poin yang akan digali adalah rumah adat, kesenian, kerajinan masyarakat, atraksi tertentu, kuburan bersejarah, bangunan/tempat bersejarah dan makanan khas.

\section{Analis Data}

\section{Flora dan Fauna}

Data flora dan fauna kemudian dianalisis Indeks Keanekaragaman Jenis menggunakan rumus Shannonwiener $\left(H^{\prime}\right)$, Indeks Kekayaan Jenis $(R)$, Indeks kemerataan (E). Selanjutnya menentukan kategori keanekaragaman jenis berdasarkan klasifikasi nilai indeks keanekaragaman jenis Shannon-Wiener.

Kerapatan (flora) didapatkan melalui perbandingan jumlah individu dengan luas keseluruhan plot, kelimpahan (fauna) didapatkan melalui jumlah individu jenis dengan jumlah keseluruhan individu kemudian dikali 100, serta frekuensi jenis didapatkan melalui perbandingan jumlah plot ditemukan jenis dengan jumlah seluruh plot dikali 100.

\section{Sosial Budaya}

Data sosial budaya masyarakat dianalisis secara deskirptif terkait budaya lokal masyarakat sekitar TWA Cani Sirenreng. 


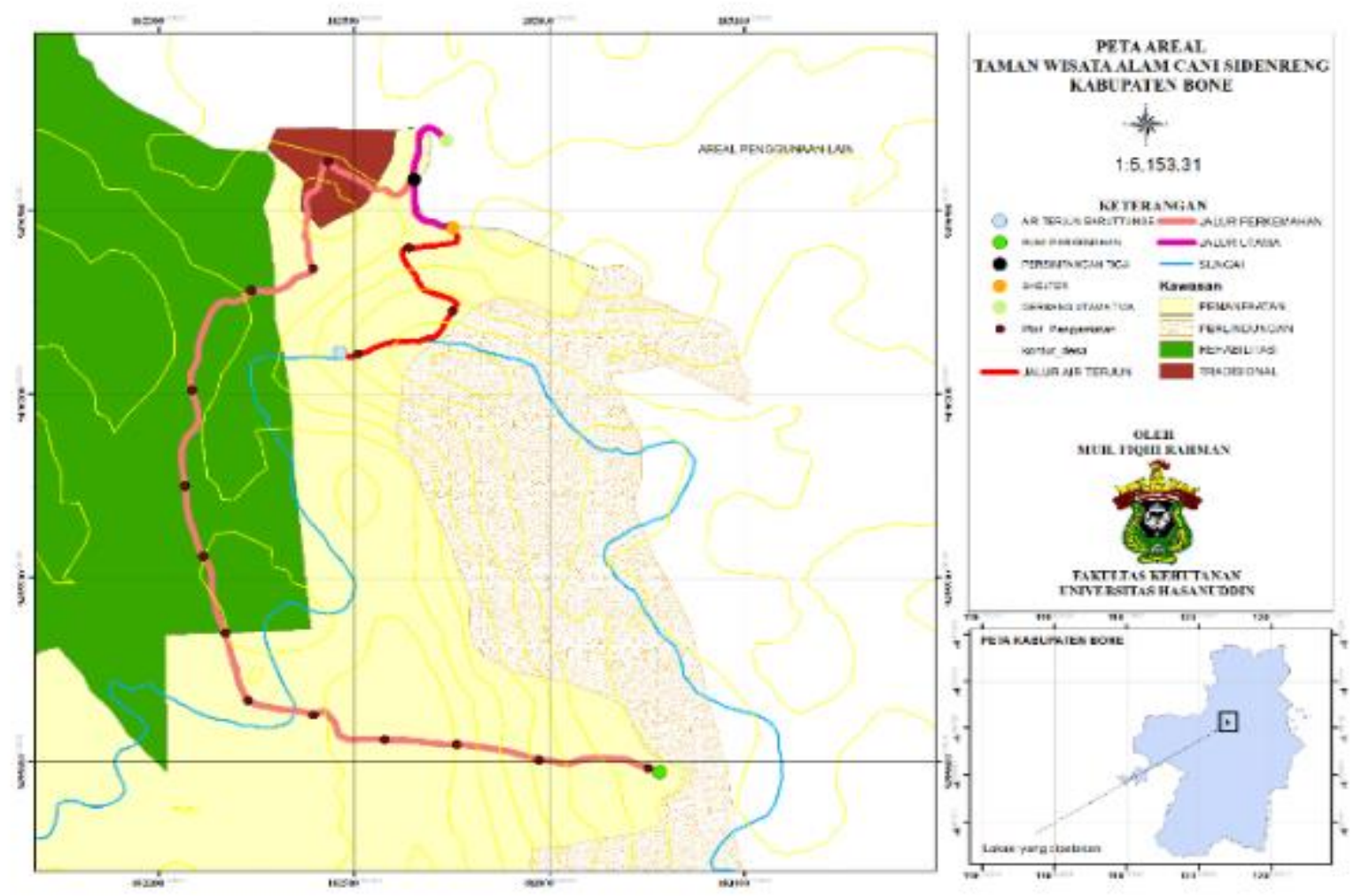

Gambar 1. Peta Jalur Wisata TWA Cani Sirenreng

Hasil interpretasi dituangkan dalam bentuk bahan interpretasi objek wisata yang akan dibuat dalam bentuk visual (papan informasi) sebagai bahan rekomendasi bagi pengelola TWA Cani Sirenreng, Kabupaten Bone.

\section{HASIL}

\section{Interpretasi Jalur Air Terjun Baruttunge}

Jalur ini merupakan jalur perjalanan yang dimulai dari pintu gerbang ke arah air terjun Baruttunge dengan panjang jalur $500 \mathrm{~m}$ dan memiliki rata-rata lebar jalur 2 meter. Pertama-tama, pengunjung akan melewati areal perkebunan dengan keadaan topografi jalur cukup landai sepanjang $100 \mathrm{~m}$. Flora yang dapat dijumpai didominasi oleh tanaman perkebunan seperti pisang, coppeng, cengkeh, aju jawa dan sereh. Lokasi ini juga dijumpai fauna seperti beberapa jenis ; burung cabai panggul hitam, cabai panggul kuning, kutilang dan bondol taruk yang ditemukan berimbang waktu pagi dan sore, sedangkan jenis cekakak sungai sering dijumpai pada waktu pagi.

Sesampai pada shelter yang memiliki jarak $200 \mathrm{~m}$ dari gerbang, tepat di lokasi ini pengunjung dapat menikmati panorama pemandangan dari jauh air terjun baruttunge. Kapuk randu, aren, jati putih, jati, mangga dan berbagai jenis tumbuhan bawah seperti kopasanda, rumput teki, dan saliara ditemukan di vegetasi hutan campuran yang berada di sekitaran jalur. Serta mengamati beberapa jenis burung diantaranya ; madu hitam, srigunting, kepudang sungu-belang yang sering ditemukan pada pagi hari sedangkan jenis madu sriganti sering ditemukan pada sore hari. Kemudian pengunjung harus melewati jalur yang topografi sedikit menurun untuk menuju ke air terjun baruttunge. Dengan keadaan vegetasi yang rapat sehingga dapat dilakukan wisata pengenalan jenis tumbuhan diantaranya jenis eboni yang memiliki status konservasi rentan (Vurnerable) pada daftar Redlist IUCN. Bambu, Bitti, Beringin, Lento-lento, Lonkida, Waru, Kersen, dan berbagai tumbuhan bawah seperti pakupakuan dan rumput gajah juga ditemukan pada areal hutan alam yang berlokasi dipinggiran sungai yang menjadi aliran Air Terjun Baruttunge.

Sebelum tiba tepat di lokasi Air Terjun Baruttunge, pengunjung akan menyusuri sebuah sungai yang sewaktu-waktu arusnya deras dan harus melewati batubatu sungai untuk bisa berada di bawah air terjun. Lokasi ini, dapat pula dilakukan pengamatan burung yang diantaranya terancam keberadaanya seperti ; elang ular Sulawesi dan gagak hutan. Jenis seperti walet dan layang-layang batu cukup mendominansi kawasan ini terutama pada sore hari, karena sangat menyukai percikan air dari air terjun baruttunge yang cukup deras jika menjelang waktu sore.

Status keanekaragaman jenis flora pada empat tingkatan pertumbuhan adalah indeks flora pada tingkatan pohon memiliki nilai tertinggi dengan nilai $\mathrm{H}^{\prime}(2,3), \mathrm{E}(0,93)$ dan $R$ (1). Sedangkan Indeks Flora pada tingkatan semai memiliki nilai terendah dengan nilai $\mathrm{H}^{\prime}(1,73), \mathrm{E}(0,89)$ dan $\mathrm{R}(0,63)$. ( Tabel 1) 
Tabel 1. Indeks Ekologi flora Jalur Air Terjun Baruttunge

\begin{tabular}{llccc}
\hline No & $\begin{array}{c}\text { Tingkatan } \\
\text { Pertumbuhan }\end{array}$ & $\begin{array}{c}\mathrm{H}^{\prime} \text { (Indeks } \\
\text { Keaneka- } \\
\text { ragaman } \\
\text { Jenis) }\end{array}$ & $\begin{array}{c}\mathrm{E} \text { (Indeks } \\
\text { Kemerataan } \\
\text { Jenis) }\end{array}$ & $\begin{array}{c}\mathrm{R} \text { (Indeks } \\
\text { Kekayaan } \\
\text { Jenis) }\end{array}$ \\
\hline 1 & Pohon & 2.3 & 0.93 & 1 \\
2 & Tiang & 1.27 & 0.92 & 1.14 \\
3 & Pancang & 1.84 & 0.88 & 1.33 \\
4 & Semai & 1.73 & 0.89 & 1 \\
\hline
\end{tabular}

Tabel 2. Indeks Ekologi fauna Jalur Air Terjun Baruttunge

\begin{tabular}{ccccc}
\hline No. & $\begin{array}{c}\mathrm{H}^{\prime} \\
\text { Jelompok } \\
\text { Jenis }\end{array}$ & $\begin{array}{c}\text { (Indeks } \\
\text { Keaneka- } \\
\text { ragaman } \\
\text { Jenis) }\end{array}$ & $\begin{array}{c}\mathrm{E} \\
\text { (Indeks } \\
\text { Kemerataan } \\
\text { jenis) }\end{array}$ & $\begin{array}{c}\text { R } \\
\text { (Indeks } \\
\text { Kekayaan } \\
\text { Jenis) }\end{array}$ \\
\hline 1 & $\begin{array}{c}\text { Aves } \\
\text { (Burung) } \\
\text { Insekta } \\
\text { (Serangga) }\end{array}$ & 1.75 & 0.66 & 0.13 \\
\hline
\end{tabular}

Status keanekaragaman jenis fauna pada kelompok jenis burung dan serangga adalah kelompok jenis serangga memiliki nilai rata-rata indeks keanekaragaman tertinggi dengan nilai $H^{\prime}(1,73), E(0,96), \quad R \quad(0,22)$ dibandingkan kelompok jenis burung yang memiliki nilai rata-rata terendah dengan nilai $H^{\prime}(1,75), E(0,66), R$ $(0,13)$. (Tabel 2)

\section{Interpretasi Jalur Coppo Cempa}

Jalur kedua merupakan jalur yang menghungkan dari jalur utama pintu gerbang TWA Cani Sirenreng ke Puncak Coppo Cempa dengan panjang jalur 1,4 km dan durasi perjalanan 1 jam. Perjalanan berawal mengitari bukit-bukit yang jalurnya cukup landai. Pengunjung akan melewati perkebunan yang ditanam oleh masyarakat sekitar. Jenis cengkeh merupakan jenis dengan jumlah tertinggi yang ditemukan diareal ini, disamping itu terdapat juga jenis seperti coppeng, jati, mangga, nangka dan aju jawa. Karena vegetasi yang cukup terbuka di sekitar perkebunan cengkeh, pengunjung dapat menikmati dan mengamati beberapa jenis burung seperti : cabai panggul hitam, kutilang, madu hitam, kekep babi, dan kancilan kelabu yang dominan ditemukan di pagi hari. Jenis layanglayang batu, cabai panggul kuning, bondol taruk, dan tekukur dominan ditemukan di sore hari. Sedangkan Jenis burung seperti ; madu sriganti dan uncuing ditemukan berimbang pada waktu pagi dan sore.

Pada pertengahan perjalanan, jalur yang dilewati memiliki topografi cukup landai. Pengunjung melewati areal yang bisa disebut kawasan kebun campuran dimana terdapat jenis tumbuhan seperti ; aren, kemiri, pangi, saga pohon, maja, akasia, berbagai jenis tumbuhan bawah seperti rumput teki, kopasanda dan saliara. Walaupun terdapat banyak tumbuhan namun kawasan ini tetap terbuka sehingga memungkinkan mengamati jenis burung yang diantaranya terancam punah seperti ; kirik-kirik australia dan gagak hutan yang dominan ditemukan pada pagi hari, sedangkan elang ular Sulawesi dan elang sayap cokelat dapat ditemukan di waktu pagi dan sore.

Pada kawasan ini juga sering ditemukan kegiatan Massari yang menjadi kebiasaan masyarakat mengola nira Aren sebagai produk gula merah. Air nira dipanen. Kegiatan penyadapan aren ini dilakukan dengan cara memukul-mukul terlebih dahulu batang aren yang berada dekat dengan tongkol menggunakan palu khusus yang terbuat dari kayu. Setelah dipukul-pukul, ujung tongkol dipotong lalu diberi wadah bambu (tongka) untuk menampung nira yang keluar dari tongkol aren tersebut. Hasil nira yang baru disadap kemudian dibawa pulang kerumah untuk dimasak menggunakan wajan besar dan tungku pembakaran yang biasa disebut balombong hingga mengental. Kemudian di cetak menggunakan petung (Bambu besar). Air nira juga biasa dijadikan minuman khas yakni Toa cenning.

Sebelum mencapai Puncak Coppo Cempa, pengunjung diharuskan menyeberangi sungai dangkal dengan lebar $7 \mathrm{~m}$. Menyeberangi sungai biasa dilakukan dengan menginjak batu sungai dengan catatan pengunjung harus berhati-hati karena rawan tergelincir. Pada kawasan ini juga menyimpan banyak tumbuhan sehingga memungkinkan untuk berteduh dan berisitirahat sambil mengamati jenis tumbuhan diantaranya pakis, lento-lento, kananga, dahu, angsana, berbagai jenis tumbuhan bawah seperti melastoma dan gletang. Jenis fauna reptil seperti kadal ketiak kuning yang sering ditemukan pada sore hari dan ular boiga juga sering dijumpai disekitaran sungai pada pagi hari.

Pada saat berjalan meninggalkan sungai, jenis seperti Kesambi, Beringin, ardisia, puspa, mangga hutan, Ionkida, berbagai jenis tumbuhan bawah seperti pakupakuan, tapal kuda, rumput gajah berada di hutan alam sekitaran jalur menuju hingga puncak Coppo Cempa. Karena jalur yang dilewati menuju coppo cempa sewaktuwaktu terbuka sehingga biasa ditemukan jenis burung seperti ; kadalan Sulawesi yang ditemukan pada pagi hari, sedangkan jenis srigunting, kepudang sungu-belang, kepudang kuduk hitam, dan mandar padi kuning sering ditemukan pada sore hari disepanjang perjalanan. Kemudian jenis serangga seperti berbagai jenis kupu-kupu (Neptis nandina, Eurema westwod,) kumbang hitam sering ditemukan pada pagi hari dan jenis kupu-kupu (Hedonia intermedia, Graphium milon dan Delias eucharis) cukup berimbang pada pagi dan sore hari yang dapat ditemukan di sepanjang jalur pengamatan menuju coppo cempa.

Barulah pengunjung dapat menginjakkan kaki di puncak coppo cempa. Pengunjung dapat menikmati areal tersebut dengan mendirikan tenda. Menikmati matahari terbit maupun terbenam, bahkan ketika keadaan cuaca cerah pengunjung juga dapat menikmati pemandangan Teluk Bone menjadi daya tarik lokasi tersebut. 
Tabel 3. Indeks Ekologi flora Jalur Coppo Cempa

\begin{tabular}{clccc}
\hline No & $\begin{array}{c}\text { Tingkatan } \\
\text { Pertumbuhan }\end{array}$ & $\begin{array}{c}\text { H' (Indeks } \\
\text { Keaneka- } \\
\text { ragaman } \\
\text { Jenis) }\end{array}$ & $\begin{array}{c}\mathrm{E} \text { (Indeks } \\
\text { Kemerataan } \\
\text { Jenis) }\end{array}$ & $\begin{array}{c}\mathrm{R} \text { (Indeks } \\
\text { Kekayaan } \\
\text { Jenis) }\end{array}$ \\
\hline 1 & Pohon & 1 & 0.79 & 0.73 \\
2 & Tiang & 2.21 & 0.89 & 0.83 \\
3 & Pancang & 1.93 & 0.93 & 1.07 \\
4 & Semai & 2.32 & 0.93 & 0.44 \\
\hline
\end{tabular}

Tabel 4 Indeks Ekologi Fauna Jalur Coppo Cempa

\begin{tabular}{ccccc}
\hline No. & $\begin{array}{c}\text { Kelompok } \\
\text { Jenis }\end{array}$ & $\begin{array}{c}\mathrm{H} \\
\text { (Indeks } \\
\text { Keaneka- } \\
\text { ragaman } \\
\text { Jenis) }\end{array}$ & $\begin{array}{c}\mathrm{E} \\
\text { (Indeks } \\
\text { Kemerataan } \\
\text { jenis) }\end{array}$ & $\begin{array}{c}\mathrm{R} \\
\text { (Indeks } \\
\text { Kekayaan } \\
\text { Jenis) }\end{array}$ \\
\hline 1 & $\begin{array}{l}\text { Aves (Burung) } \\
\text { Insekta }\end{array}$ & 1.75 & 0.56 & 0.08 \\
2 & $\begin{array}{l}\text { (Serangga) } \\
3\end{array}$ & 1.68 & 0.94 & 0.24 \\
\hline
\end{tabular}

Nilai keanekaragaman jenis flora pada empat tingkatan pertumbuhan adalah indeks Flora pada tingkatan Pancang memiliki nilai tertinggi dengan nilai $\mathrm{H}^{\prime}$ $(1,93)$, E $(0,93)$ dan $R(1.07)$. Sedangkan Indeks Flora pada tingkatan pohon memiliki nilai terendah dengan nilai $H^{\prime}(1), E(0,79)$ dan $R(0,73)$. (Tabel 3 )

Status keanekaragaman jenis fauna pada kelompok jenis burung dan seranggga adalah kelompok jenis serangga memiliki nilai rata-rata indeks keanekaraganan tertinggi dengan nilai $H^{\prime}(1,68), \quad E(0,94), \quad R \quad(0,24)$ dibandingkan kelompok jenis burung memiliki nilai ratarata terendah dengan nilai $H^{\prime}(1,75), E(0,56), R(0,08)$. (Tabel 4).

\section{PEMBAHASAN}

Guna mewujudkan Interpretasi Objek Wisata di Taman Wisata Alam Cani Sirenreng diperlukan bahan interpretasi sebagai sarana utama dalam kegiatan ekowisata. Bahan yang dibutuhkan berupa hasil identifkasi objek wisata yang tersebar di jalur jalan setapak di TWA Cani Sirenreng yaitu objek wisata fisik, objek wisata biologi dan objek wisata sosial budaya. Jalur jalan setapak yang tersedia di TWA Cani Sirenreng yaitu Jalur Air Terjun Baruttunge dan Jalur Coppo Cempa.

Jalur Air Terjun Baruttunge dilalui dari pintu gerbang menuju air terjun Baruttunge dengan jarak $500 \mathrm{~m}$. menghadirkan Air Terjun Baruttunge yang menjadi objek primadona TWA Cani Sirenreng dengan total ketinggian 70 meter dan bersusun tiga. Objek wisata biologi juga dapat dilakukan dijalur ini dengan kegiatan pengamatan tumbuhan karena terdapat jenis eboni. Jenis eboni masuk dalam kategori rentan (Vurnerable) pada Redlist IUCN. Kegiatan pengamatan tumbuhan dapat didukung dengan metode interpretasi tidak langsung seperti papan tanda informasi/ karakteristik jenis (Sharpe, 1982). Terdapat juga jenis elang ular sulawesi yang status konservasinya berada ditingkatan resiko rendah (LC) di Redlist IUCN dan jenis burung bilbong pendeta dan kepudang sungu belang yang endemik di Sulawesi.

Sedangkan Jalur Coppo Cempa dimulai dari pintu gerbang menuju puncak Coppo Cempa dengan jarak 1,4 $\mathrm{km}$. Objek fisik yang dihadirkan berupa areal perbukitan yang biasa dijadikan lokasi perkemahan dan kegiatan hicking. Lokasi ini memiliki daya tarik pemandangan barisan bukit yang berjejeran disekitarnya. Keunggulan di jalur ini terdapat jenis burung elang ular Sulawesi, burung elang sayap cokelat, burung dan kirik-kirik Australia yang status konservasinya berada di tingkatan resiko rendah (LC) di Redlist IUCN dan jenis burung kadalan sulawesi dan kepudang sungu belang yang merupakan jenis endemik di Sulawesi. Sehingga di jalur ini dapat dilakukan kegiatan birdwatching. Pada dasarnya bentuk kegiatan birdwatching adalah perjalanan ke alam bebas dengan penekanan pada apresiasi manusia terhadap keindahan burung yang hidup bebas di habitatnya, baik kemerduan suara, keindahan bentuk dan warna tubuh, maupun keunikan tingkah lakunya (www.kehati.or.id, 2000). Disamping itu juga terdapat objek sosial budaya dimana tradisi masyarakat sekitar memanen nira aren atau massari untuk dijadikan gula merah.

Keunggulan yang sudah didapatkan dari setiap jalur akan di tampilkan sebagai informasi bagi pengunjung. Menurut Sitepu (2003) dalam menyusun rencana interpretasi, kawasan wisata alam biasanya dilengkapi dengan bangunan pusat informasi, yang dapat memberikan gambaran bagi pengunjung mengenai apa saja yang dapat dilihat, diketahui dipelajari di kawasan tersebut. Pemasangan papan tanda juga sangat sangatlah penting karena dapat memberi kemudahan kepada pengunjung ketika masuk ke dalam kawasan wisata alam, agar tidak tersesat, mendapatkan perjalanan efektif, mengetahui larangan/aturan dalam di kawasan, serta menginformasikan jarak tempuh suatu objek.

Selain informasi objek yang berada dijalur, juga terdapat diluar kawasan TWA Cani Sirenreng yaitu objek sosial budaya Menurut Fandelli, dkk. (2001) masyarakat sekitar harus dilibatkan dalam pengembangan ekowisata seperti pengawasan ataupun dapat menjadikan keuntungan ekonomi. Di dalam Masyarat terdapat aspek sosial budaya yang akan menjadi daya tarik wisata karena memiliki keunikan dan kekhasan tersendiri seperti di TWA Cani Sirenreng yang masyarakatnya didominasi budaya Bugis Bone. Namun yang menjadi kendala, kurangnya regenerasi dari pemuda desa dalam melestarikan budaya, serta inisiatif dari pemerintah desa dalam melestarikan budaya lokal yang semakin lama semakin tergerus oleh 
Tabel 5. Potensi Sosial Budaya

\begin{tabular}{|c|c|c|c|}
\hline No & $\begin{array}{l}\text { Potensi } \\
\text { Budaya }\end{array}$ & $\begin{array}{c}\text { Jenis Potensi } \\
\text { Budaya }\end{array}$ & Deksripsi \\
\hline 1 & Ritual Adat & $\begin{array}{l}\text { - Maccudang- } \\
\text { cudangeng }\end{array}$ & $\begin{array}{l}\text { - Kegiatan Silatuhrahmi makan bersama warga sekitar TWA Cani Sirenreng } \\
\text { khususnya di Dusun Bobojong, Desa Cani Sirenreng. Bertujuan untuk memberikan } \\
\text { rasa syukur kepada Tuhan Yang Maha Esa atas nikmat air. }\end{array}$ \\
\hline 2 & Kesenian & - Mappadekko & $\begin{array}{l}\text { - Sebuah permainan musik tradisional masyarakat bugis yang juga biasa dikenal } \\
\text { dengan istilah Mappadendang. Merupakan bentuk suka cita dan rasa syukur kepada } \\
\text { Tuhan Yang Maha Esa setelah melakukan panen raya. }\end{array}$ \\
\hline \multirow[t]{3}{*}{3.} & Atraksi & - Ma'lanca & $\begin{array}{l}\text { - Kegiatan atraksi bela diri yang dilakukan pemuda dalam menyambut pesta panen } \\
\text { padi. Kegiatan ini dilakukan dengan cara saling menendang kaki satu sama lain } \\
\text { secara bergantian tiga kali kesempatan. }\end{array}$ \\
\hline & & - Ma'sempe & $\begin{array}{l}\text { - Kegiatan atraksi bela diri tradisional yang juga menjadi khas masyarakat Bugis Bone } \\
\text { saat menyambut panen raya. Massempe'adalah melakukan suatu pertarungan } \\
\text { dengan cara menendang ataupun menyepak lawan. }\end{array}$ \\
\hline & & - Ma'raga & $\begin{array}{l}\text { - Sebuah atraksi yang meperagakan permainan bola yang terbuat dari anyaman rotan. } \\
\text { Permainan ini mengandung unsur olahraga dan seni yang tinggi.. menggunakan kaki, } \\
\text { kepala, lutut bahkan tangan dalam mempertahankan bola selama mungkin dengan } \\
\text { beberapa joget khas. }\end{array}$ \\
\hline 4 & $\begin{array}{l}\text { Kuburan } \\
\text { Tua }\end{array}$ & $\begin{array}{l}\text { - Salewatang } \\
\text { Cambulung } \\
\text { bulung }\end{array}$ & $\begin{array}{l}\text { - Kuburan tua keturunan Arung (Bangsawan bugis) yang biasa dikeramatkan oleh } \\
\text { masyrakat sekitar yang mempercayai hal-hal mistis. Kuburan tersebut berada di } \\
\text { dusun Paccongkai, Desa Cani Sirenreng. }\end{array}$ \\
\hline \multirow[t]{3}{*}{5} & Tradisi & - Ma'sari & $\begin{array}{l}\text { - Kegiatan penyadapan aren ini dilakukan dengan memukul-mukul terlebih dahulu } \\
\text { batang aren yang berada dekat dengan tongkol. Setelah dipukul-pukul, ujung } \\
\text { tongkol dipotong lalu diberi wadah bambu (tongka) untuk menampung nira yang } \\
\text { keluar dari tongkol aren tersebut. }\end{array}$ \\
\hline & & $\begin{array}{l}\text { - Mappatettong } \\
\text { bola }\end{array}$ & $\begin{array}{l}\text { - Sebuah kegiatan gotong royong masih dilestarikan warga bugis unuk membuat } \\
\text { rumah panggung (rumah adat bugis). Pertama-tama dilakukan upacara sebagai } \\
\text { permohonan doa restu. Sehari menjelang didirikan, maka pada malam harinya } \\
\text { dilakukan pembacaan kitab Barzanji. Biasanya dilaksanakan oleh seluruh } \\
\text { masyarakat }\end{array}$ \\
\hline & & - Marakka Bola & $\begin{array}{l}\text { - Merupakan kegiatan pindah rumah khas suku bugis yang berarti memindahkan } \\
\text { rumah seutuhnya tanpa dibongkar-bongkar untuk dibawa ke lokasi yang baru. Kita } \\
\text { bisa melihat budaya gotong royong warga satu kampung yang sekarang ini sudah } \\
\text { mulai langka dan sangat jarang dijumpai. }\end{array}$ \\
\hline
\end{tabular}

perkembangan zaman. Maka dengan adanya informasi mengenai potensi budaya yang keberadaanya semakin tergerus seperti : mappadekko, ma'lanca dan ma'sempe dapat dihadirkan kembali guna memberikan keuntungan wisata, edukasi maupun keuangan bagi pelaku ekowisata.

Sarana juga perlu diperhatikan di TWA Cani Sirenreng ini seperti aksesibilitas. Aksesibilitas merupakan unsur terpenting dalam pembentukan produk wisata. Aksesibilitas meliputi transportasi maupun akses jalan (Yoeti, 1997). Transportasi ke lokasi TWA Cani Sirenreng cukup mudah dijangkau yang hanya berjarak $2 \mathrm{~km}$ dari jalan Poros Bone-Makassar dengan kondisi jalan beraspal. Salah satu unsur penting pembentuk produk pariwisata setelah aksesibilitas adalah fasilitas wisata, yang berperan menunjang kemudahan dan kenyamanan wisatawan, seperti; ketersediaan sarana akomodasi, prasarana wisata dalam radius tertentu dan sarana wisata pendukung lainnya. Di kawawan ini terdapat toilet yang belum sepenuhnya rampung sehingga tidak dapat digunakan. Sedangkan shelter sudah ada walaupun belum selesai pengerjaannya. Di TWA Cani Sirenreng juga tidak disedikan tempat parkir khusus, sehingga sangat disarankan untuk dibuatkan lahan parkir walaupun sampai saat ini pengunjung menggunakan halaman rumah masyarakat sekitar sebagai lahan parkir.

\section{E. KESIMPULAN}

1) Objek wisata yang dijadikan sebagai jalur interpretasi adalah Jalur Air Terjun Baruttunge dan Jalur Coppo Cempa di Taman Wisata Alam Cani Sirenreng.

2) Objek wisata di Jalur Air Terjun Baruttunge terdiri dari 1 objek fisik, 44 objek biologi yang terdiri dari 24 flora dan 20 fauna. Yang menarik di jalur ini yaitu adanya jenis tumbuhan eboni yang merupakan jenis endemik Sulawesi dan dilindungi sehingga dapat dilakukan pengamatan tumbuhan.

3) Objek wisata di Jalur Coppo Cempa terdiri dari 1 objek fisik, 63 objek biologi yang terdiri dari 32 flora dan 31 fauna dan 1 objek sosial budaya yaitu massari. Yang 
menarik di jalur ini yaitu dapat dilakukan kegiatan birdwatching karena terdapat 27 jenis burung yang diantaranya endemik Suawesi dan keberadaanya dilindungi.

4) Objek wisata sosial dan budaya selebihnya dijumpai di luar kawasan TWA Cani Sirenreng sebanyak 9 objek.

\section{DAFTAR PUSTAKA}

Balai Konservasi Sumber Daya Alam (BKSDA) SULSEL. (2013). Penyusunan Desain Tapak Pengelolaan Pariwisata Alam TWA Cani Sirenreng. Makassar: Balai Konservasi Sumber Daya Alam (BKSDA) SULSEL

Departemen Kehutanan. (1990). Undang-Undang No.5 Tahun 1990 tentang Konservasi Sumberdaya Alam Hayati dan Ekosistemnya.

Fandeli, C., \& Mukhlison. (2000). Pengusaha Ekowisata. Yogyakarta: Fakultas Kehutanan Universitas Gadjah Mada.
Mahmud, N.F. (2010). Konservasi Hutan Manggrove Sebagai Hutan Ekowisata. Skripsi pada Fakultas Teknik Sipil dan Perencanaan Universitas Pembangunan Nasional Veteran Jawa Timur.

Sharpe, G.W. (1982). Interpreting The Environment. Second Edition. Outdoor Recreation Collage of Forest Resources Universtiy of Washington.

Sitepu, P. (2003). Perencanaan Progran Interpretasi Lingkungan Pada Dua Jalur Pendakian Gunung Sibayak Taman Hutan Raya Bukit Barisan Sumatera Utara. Skripsi pada Jurusan Konservasi Sumberdaya Hutan Fakultas Pertanian Institut Pertanian Bogor.

Soedargo, S., \& Alikodra, H.S. (1989). Interpretasi Lingkungan. Media Konservasi, 2 (3): 49-53.

Yoeti, H.O.A. (1996). Pengantar IImu Pariwisata. Bandung: Penerbit Angkasa. 